\title{
Relationship among the variables of kinematic and tilt angle of whole body according to the foot trip during gait
}

\author{
Young-Churl Ko', Che-Cheong Ryew², Seung-Hyun Hyun ${ }^{2, *}$ \\ 'Department of Journalism and Public Relations, College of Social Science, Jeju National University, Jeju, Korea \\ ${ }^{2}$ Department of Kinesiology, College of Natural Science, Jeju National University, Jeju, Korea
}

The aim of this study was to analyze the relation between incline angle of whole body and kinematic variables at tripping during gait. The participants consisted of healthy adult female $(n=6)$. The three-dimensional (3D) motion analysis of posture restoring after inducing tripping of right foot at supporting phase of left foot was performed. As a result, supporting time elapsed of one stride and one foot at tripping showed longer than that of normal gait. The length of one stride showed longer at tripping than that of normal gait, and velocity of center of gravity (COG) showed faster at tripping than that of normal gait. Anteriorposterior incline angle of whole body showed more forwarded incline at tripping than that of normal gait. As a result of correlation among variables, one stride and supporting time elapsed showed positive relation $r=0.973\left(R^{2}=0.947, P<0.001\right)$, also $r=0.920\left(R^{2}=0.846, P<0.001\right)$ relative to velocity of COG, $r=0.970\left(R^{2}=0.941, P<0.001\right)$ of 1 -stride time elapsed relative to velocity of $\mathrm{COG}$ and $r=0.833\left(R^{2}=0.613, P<0.05\right)$ of velocity of $\mathrm{COG}$ relative to anteriorposterior incline angle respectively. Therefore instantaneous stoppage of gait posture when tripped at supporting phase of one leg during gait may be impossible and rather may cause a recovery of gait pattern when secured the faster velocity of COG and the longer of supporting time elapsed of one leg.

Keywords: Gait, Foot trip, Tilt angle of whole body, Stance phase

\section{INTRODUCTION}

Gait stability can be defined as the ability to maintain functional locomotion despite perturbations (England and Granata, 2007). As a minimum, this ability is provided by position- and velocity-dependent resistance to perturbation-elicited deviations from the ongoing locomotion (Krasovsky et al., 2012). Gait stability depends on the interplay between central and peripheral factors, which include the central pattern generator, muscle-reflex properties, and the mechanical interaction of the body with the environment (Taga et al., 1991).

As of the former, locomotion on level have no difficulty due to improved function of gait stability, but often cause falling injuries by irregular surface and nonperceived visually, thus may cause serious problem in that an unexpected burden of medical expense and a lowering of living quality cause (Smeesters et al., 2001).

Mostly falling injuries occur in pathological gait or the old age, but performed preceded studies on the recovery response of posture after inducing tripping with young adult (Eng et al., 1994; Forner Cordero et al., 2003; Grabiner et al., 1993; Grabiner et al., 1996; Schillings et al., 2000; Smeesters et al., 2001) because tripping is one of the source of the falling injuries during gait (Berg et al., 1997; Blake et al., 1988; Nevitt et al., 1991).

When summarizing the above studies, preventing of falling injuries after tripping was to reduce angular momentum generated from impact between obstacle and body. Particularly one of how to reduce angular momentum was to protract lower-leg more forwardly than center of gravity (COG) position in order to generate muscle power forward direction of gait (Grabiner et al., 1993; Grabiner et al., 1996; Pavol et al., 2001), and thus trip leg is necessary to perform a delaying role in case of stance limb at time of tripping until the trip leg touch-down (Pijnappels et al., 2004).

But afterwards studies considered irregular conditions of ground performing gait ground and intended manipulation of the
${ }^{*}$ Corresponding author: Seung-Hyun Hyun (iD http://orcid.org/0000-0001-6348-6413 Department of Kinesiology, College of Natural Science, Jeju National University, 102 Jejudaehak-ro, Jeju 63243, Korea

Tel: +82-64-754-3580, Fax: +82-64-757-1752, E-mail: hshyun0306@jejunu.ac.kr Received: October 7, 2016 / Accepted: January 31, 2017
This is an Open Access article distributed under the terms of the Creative Commons Attribution Non-Commercial License (http://creativecommons.org/licenses/by-nc/4.0/) which permits unrestricted non-commercial use, distribution, and reproduction in any medium, provided the original work is properly cited. 
obstacle is necessary and particularly on posture recovery by inducing tripping and response. Because moment of hip, knee, and ankle joint increases relative to faster locomotion velocity in case of young adult and juvenile than the old age (Schultz, 1995), these tripping may resulted in unrecoverable motor ability and serious handicapped situation. Therefore it is necessary to diagnosis an injury part through epidemiologic survey helpful for rehabilitation and treatment relative to types of tripping during gait, but rare materials.

The aim of this study was to analyze quantitatively correlation among variables of gait characteristics and incline angle of whole body by inducing tripping with young female.

\section{MATERIALS AND METHODS}

\section{Subject}

The subjects participated in the study consisted of adult female $(\mathrm{n}=6$; mean age, $21.83 \pm 0.75$ years; mean height, $159.91 \pm 4.16$ $\mathrm{cm}$; mean weight; $56.05 \pm 8.82 \mathrm{~kg}$ ). Participants were explained on the aim and experimental details and gave the written consent.

\section{Experimental procedure}

The experiment was performed tripping situation during gait on gym. Floor and set up 4 camera (HDR/HDV 1080i, Sony Corp., Tokyo, Japan) to capture the gait motion and lighting facilities. Control object box $(2 \mathrm{~m} \times 2 \mathrm{~m} \times 1 \mathrm{~m})$ attached with 36 points for real spatial coordinates was filmed for 5 sec before filming for subjects.

Body segment parameters for film analysis was attached on each joint of the subject with the 31 reflexive markers (right-left toe, right.left heel, right.left lateral-medial malleolus, right-left shank,

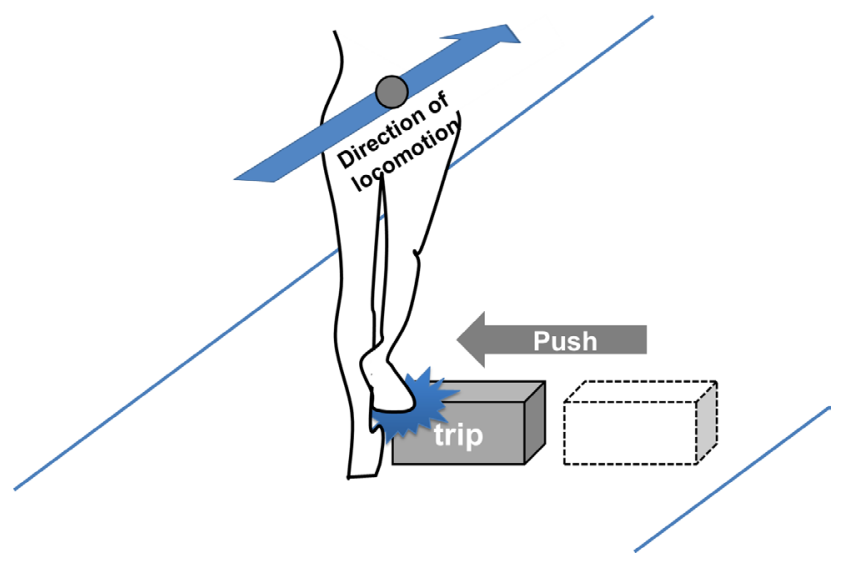

Fig. 1. Trip of right foot during left foot stance. right.left lateral-medial epicondyle, right.left thigh, right.left anterior superior iliac spine, sacrum, right.left lateral-medial wrist, right-left lateral-medial elbow, right.left shoulder, chin, nose) on the basis of (Plagenhoef et al., 1983).

As of Fig. 1 to prevent a risk of falling and other's injuries, safety mat was spread out in front of gait direction and in right and left lateral direction. In particular subjects were blinded visual information with an eye patch in order not to predict a point of tripping time and controlled not to perceive the distance information after randomly performed the locomotion forward anteriorposterior direction.

That is, tripping situation was not being fixed on gait path, obstacle was positioned in front of right foot after confirming a point of left foot supporting phase of subjects (Fig. 1). After performance of tripping by 5 times individually, successful trial was utilized for analysis. Then, gait direction was defined as $y$-axis of forward, $\mathrm{x}$-axis of laterals and $\mathrm{y}$-axis of vertical direction to $\mathrm{y}$-x axis direction.

\section{Definition of analysis phase}

Supporting phase of one leg was set up on the basis of left foot, and then velocity of COG was analyzed from take-off after supporting phase of left foot, Incline angle of whole body in anteriorposterior direction (Fig. 2) was set up as range of motion (ROM) in anteriorposterior direction for projected vector of left foot-toe and chin to vertical line in sagittal plane.

\section{Analysis and process of data}

Kwon3D XP v4.0 (Visol Inc., Gwangmyeong, Korea, 2007)

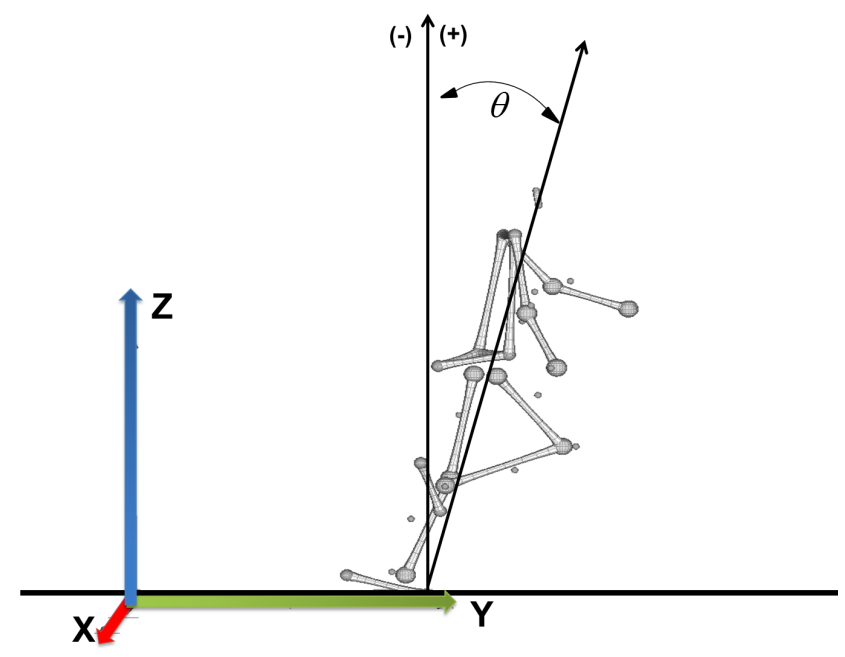

Fig. 2. Front-rear tilt angle of whole body. 
was used to process obtain kinetic variables during gait and tripping. The kinetic variables were calculated using a control point, body-joint coordinate transformation and tuning, while the 3D coordinates were calculated using the direct linear transformation method. The cutoff frequencies obtained using the Butterworth low-pass filtering method were smoothed at $6 \mathrm{~Hz}$ to remove the noise before using them as data. The reconstruction error of the 36-point 3D coordinate was confirmed to be $0.0473 \mathrm{~cm}$. The average and the standard deviation of the calculated variables were obtained using IBM SPSS Statistics ver. 22.0 (IBM Co., Armonk, $\mathrm{NY}, \mathrm{USA}$ ) and paired $t$-test was to draw comparisons between the two gaits $(\boldsymbol{\alpha}=0.05)$.

\section{RESULTS}

The gait characteristics relative to tripping showed as Table 1. Supporting phase and 1-stride time elapsed showed more delayed in tripping than that of normal gait and showed significant $(P<0.001)$. Length of one stride in tripping showed longer than that of normal gait, and showed significant $(P<0.001)$. Max change of velocity of COG during left supporting phase showed faster in tripping than that of normal gait and showed significant $(P<0.001)$. Incline angle of anteriorposterior direction of whole body showed more ROM in tripping than that of normal gait and showed significant $(P<0.01)$.
The correlation relative to tripping showed as Table 2 and Fig. 3. Supporting time and 1-stride time elapsed showed high correlation $(r=0.973)$, and showed significant $(P<0.01)$. Relation between supporting time and change of COG velocity showed high positive correlation $(r=0.920)$, showed significant $(P<0.05)$. Change of COG velocity and incline angle in anteriorposterior direction showed high positive correlation $(r=0.784)$, and showed significant.

\section{DISCUSSION}

If steady-state walking is not regained following perturbation, a fall may occur (Krasovsky et al., 2013). The study analyzed kinematic variables and its correlation on the change of posture before falling by inducing the tripping of right foot during gait.

Analysis of supporting time elapsed and 1-stride time elapsed of left foot showed more delayed in tripping than that of normal gait as of $37.35 \%$ and $61.74 \%$ respectively and gait length showed increased tendency of $36.37 \%$ in tripping than that of normal. The result showed similar gait pattern to Pijnappels et al. (2004) shown to be more supporting time and 1-stride length in tripping than that of normal gait. Also Pijnappels et al. (2005) reported that only sufficient power from supporting leg at push-up phase during gait cycle may cause posture recovery and decrease angular momentum of body. When compared with this study,

Table 1. Kinematic variables during walking

\begin{tabular}{|c|c|c|c|c|c|}
\hline \multirow{2}{*}{ Section } & \multicolumn{2}{|c|}{ Walking } & \multirow{2}{*}{$\%$} & \multirow{2}{*}{$t$} & \multirow{2}{*}{$P$-value } \\
\hline & Normal & Tripping & & & \\
\hline Stance time (sec) & $0.54 \pm 0.06$ & $0.74 \pm 0.04$ & $37.35 \pm 19.20$ & 6.806 & $<0.001^{* * *}$ \\
\hline 1-Step time (sec) & $0.45 \pm 0.04$ & $0.72 \pm 0.04$ & $61.74 \pm 20.56$ & 10.964 & $<0.001^{* * *}$ \\
\hline 1-Step lengths (cm) & $71.77 \pm 3.56$ & $97.66 \pm 3.36$ & $36.37 \pm 8.31$ & 14.360 & $<0.001^{* * *}$ \\
\hline Velocity of COG $(\mathrm{cm} / \mathrm{sec})$ & $146.57 \pm 12.95$ & $201.63 \pm 6.87$ & $38.62 \pm 14.78$ & 9.295 & $<0.001^{* * *}$ \\
\hline Front-rear angle of whole body $\left({ }^{\circ}\right)$ & $14.89 \pm 2.37$ & $29.33 \pm 7.86$ & $105.17 \pm 80.68$ & 4.139 & $0.006^{* *}$ \\
\hline
\end{tabular}

Values are presented as mean \pm standard deviation.

COG; center of gravity.

${ }^{* *} P<0.01 .{ }^{* * *} P<0.001$

Table 2. Correlationship relative to front-rear angle of trunk and kinematic variables during walking

\begin{tabular}{lccccc}
\hline Section & Stance time & 1-Step time & 1-Step lengths & Velocity of COG & F-R angle \\
\hline Stance time & - & $0.973^{* *}$ & 0.661 & $0.920^{*}$ & 0.582 \\
1-Step time & - & - & 0.610 & $0.970^{* *}$ & 0.680 \\
1-Step lengths & - & - & - & -538 & 0.148 \\
Velocity of COG & - & - & - & - & $0.833^{*}$ \\
\hline
\end{tabular}

COG; center of gravity, F-R angle; front-rear tilt angle of whole body.

${ }^{*} P<0.05 .{ }^{*} P<0.001$. 

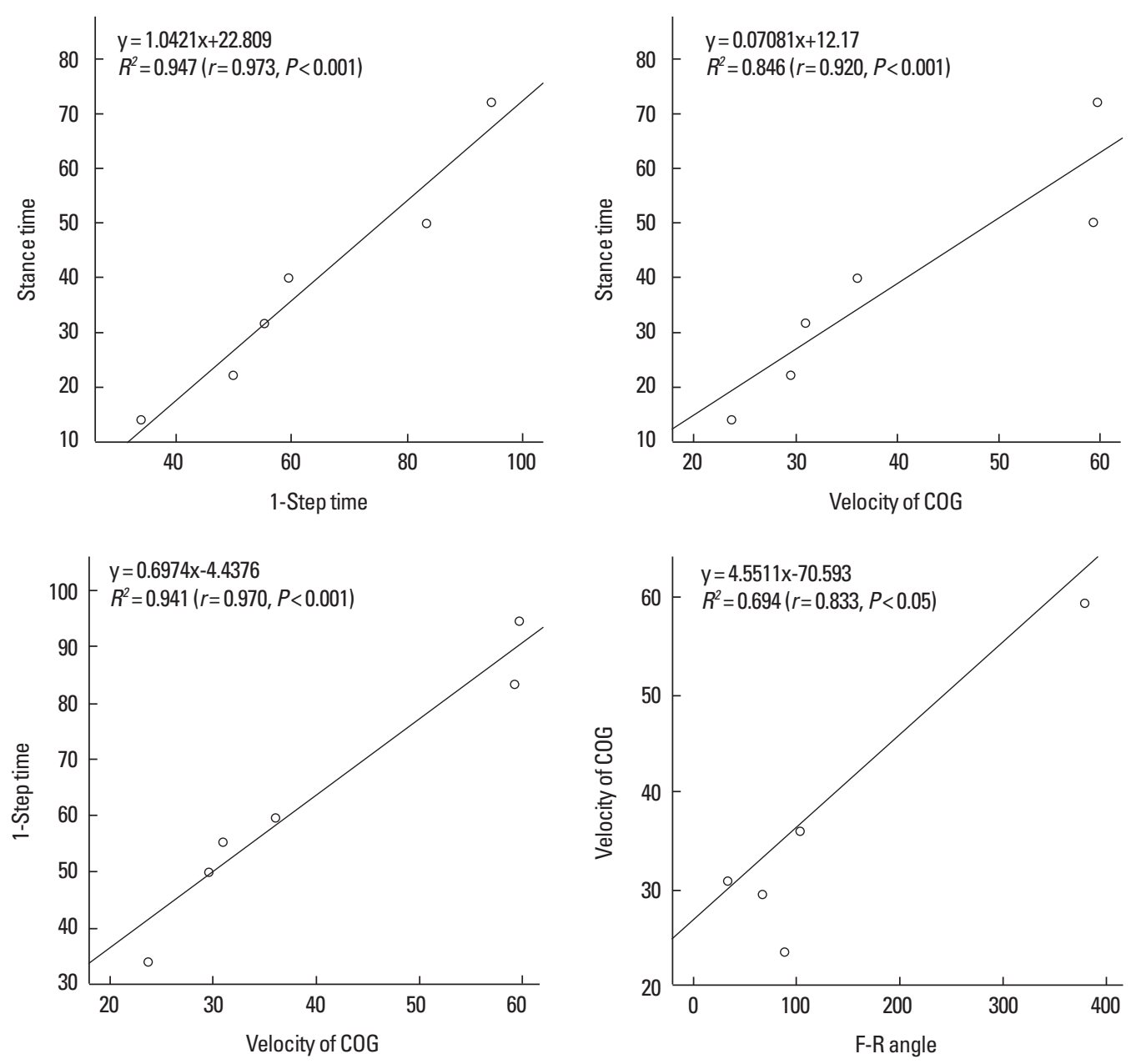

Fig. 3. Scatter plot and coefficient of determination. COG, center of gravity; F-R angle, front-rear tilt angle of whole body.

time delay of supporting leg provides a room of time deciding touch-down position of recovery leg and this mechanism are helpful for dynamic stability and control of leg position.

Particularly change of COG velocity showed faster (36.62\%) in tripping than that of normal gait and correlation between supporting time and 1-stride time elapsed $\left(r=0.973, R^{2}=0.947\right.$, $P<0.001)$ showed positive correlation, and $r=0.920\left(R^{2}=0.846\right.$, $P<0.001)$ with change of COG velocity and $r=0.970\left(R^{2}=0.941\right.$, $P<0.001)$ with 1 -stride time elapsed. That is, when tripped during gait, it may prevent falling injuries by counteraction of angular momentum and recovery of dynamic pattern of the faster forward velocity of COG.

Forward incline angle showed more ROM in tripping than that of normal as of increase of $105 \%\left(r=0.833, R^{2}=0.613, P<0.05\right)$. The result shown due to fast forward incline angle of whole body as a result of failure of forward locomotion of supporting foot during tripping. Thus because of instantaneous stoppage is impossible during tripping, It may bring about effective prevention of falling injury and decrease of angular momentum by protraction of trunk in front of COG position.

That is, when tripped at one leg supporting phase during gait, instantaneous stoppage may be impossible due to forward velocity of COG and angular momentum. In case of sufficient time and the faster forward velocity of COG, it may recover an imbalance of tripping, but may increase possibility of falling injury due to difficulty to counteract an angular momentum if increased velocity of COG, wearing of bag and carrying of bag before tripping.

\section{CONFLICT OF INTEREST}

No potential conflict of interest relevant to this article was reported. 


\section{ACKNOWLEDGMENTS}

This study rehearsed tripping of foot and collision of shoulder on the basis of the evidence 5-2 of result of kinematics analysis on the collision between male and female appeared in CCTV (file name: 9:00 p.m., November 15, 2014. Investigator Jin-Soo Jo: $\mathrm{mp} 4)$. The aim of the study, on the one hand, quantitative analysis of posture change of female at tripping of foot, on the other hand without displacement of two legs at predicted area of collision, whether motion of instantaneous stoppage and squat-down at origin place may bring about.

This research was supported by the 2016 scientific promotion program funded by Jeju National University.

\section{REFERENCES}

Berg WP, Alessio HM, Mills EM, Tong C. Circumstances and consequences of falls in independent community-dwelling older adults. Age Ageing 1997;26:261-268.

Blake AJ, Morgan K, Bendall MJ, Dallosso H, Ebrahim SB, Arie TH, Fentem PH, Bassey EJ. Falls by elderly people at home: prevalence and associated factors. Age Ageing 1988;17:365-372.

Eng JJ, Winter DA, Patla AE. Strategies for recovery from a trip in early and late swing during human walking. Exp Brain Res 1994;102:339349.

England SA, Granata KP. The influence of gait speed on local dynamic stability of walking. Gait Posture 2007;25:172-178.

Forner Cordero A, Koopman HF, van der Helm FC. Multiple-step strategies to recover from stumbling perturbations. Gait Posture 2003;18:4759.

Grabiner MD, Feuerbach JW, Jahnigen DW. Measures of paraspinal muscle performance do not predict initial trunk kinematics after tripping. J Biomech 1996;29:735-744.
Grabiner MD, Koh TJ, Lundin TM, Jahnigen DW. Kinematics of recovery from a stumble. J Gerontol 1993;48:M97-102.

Krasovsky T, Baniña MC, Hacmon R, Feldman AG, Lamontagne A, Levin MF. Stability of gait and interlimb coordination in older adults. J Neurophysiol 2012;107:2560-2569.

Krasovsky T, Lamontagne A, Feldman AG, Levin MF. Reduced gait stability in high-functioning poststroke individuals. J Neurophysiol 2013; 109:77-88.

Nevitt MC, Cummings SR, Hudes ES. Risk factors for injurious falls: a prospective study. J Gerontol 1991;46:M164-170.

Pavol MJ, Owings TM, Foley KT, Grabiner MD. Mechanisms leading to a fall from an induced trip in healthy older adults. J Gerontol A Biol Sci Med Sci 2001;56:M428-437.

Pijnappels M, Bobbert MF, van Dieën JH. Contribution of the support limb in control of angular momentum after tripping. J Biomech 2004; 37:1811-1818.

Pijnappels M, Bobbert MF, van Dieën JH. Push-off reactions in recovery after tripping discriminate young subjects, older non-fallers and older fallers. Gait Posture 2005;21:388-394.

Plagenhoef S, Evans FG, Abdelnour T. Anatomical data for analyzing human motion. Res Q Exerc Sport 1983;54:169-178.

Schillings AM, van Wezel BM, Mulder T, Duysens J. Muscular responses and movement strategies during stumbling over obstacles. J Neurophysiol 2000;83:2093-2102.

Schultz AB. Muscle function and mobility biomechanics in the elderly: an overview of some recent research. J Gerontol A Biol Sci Med Sci 1995;50 Spec No:60-63.

Smeesters C, Hayes WC, McMahon TA. The threshold trip duration for which recovery is no longer possible is associated with strength and reaction time. J Biomech 2001;34:589-595.

Taga G, Yamaguchi Y, Shimizu H. Self-organized control of bipedal locomotion by neural oscillators in unpredictable environment. Biol Cybern 1991;65:147-159. 